FERREIRA, Letícia Carvalho de Mesquita. 2009. Dos autos da cova rasa: a identificação de corpos não identificados no Instituto Médico-Legal do Rio de Janeiro. Rio de Janeiro: E-papers/LACED/Museu Nacional. 198 pp.

\section{Juliana Farias}

Doutoranda - PPGSA/IFCS/UFRJ

Quantas pesquisas antropológicas nos informam sobre o encontro entre um homem desconhecido (já morto) e um servente de pernoite do IML-RJ? Dos autos da cova rasa está repleto de encontros como estes - insignificantes aos olhos de muitos. Atribuindo-lhes relevância social e científica, Letícia Carvalho de Mesquita Ferreira enquadra-os em sua investigação sobre o processo de identificação dos corpos não identificados que, entre 1942 e 1960, se encontravam assim designados no Instituto Médico-Legal do Rio de Janeiro (IML-RJ).

A ausência de registro de nome próprio na documentação analisada por Ferreira (2009) é, ao mesmo tempo, traço comum do material selecionado e condição de possibilidade da pesquisa: "foram mortes que originaram documentos destituídos do privilégio do sigilo burocrático" (:162). Como explica a autora, o acesso ao material - parte da série "Mortos", ou de exames cadavéricos, do fundo Instituto Médico Legal do Arquivo Público do Estado do Rio de Janeiro (Aperj) - foi relativamente facilitado devido ao seu interesse nos casos de pessoas não identificadas, visto que uma das exigências institucionais àqueles que desejassem trabalhar com o mesmo fundo documental era o compromisso com a não divulgação dos nomes dos periciados.

O período recortado para a análise está diretamente ligado às especificidades do arquivo pesquisado: não só o número reduzido de alterações na legislação e na estrutura administrativa do IML-RJ entre os anos de 1942 e 1960 foi levado em conta, como também o fato de os formulários da instituição correspondentes a esse período terem sofrido menos modificações. Ferreira descreve de forma detalhada as escolhas metodológicas desta pesquisa em arquivo, designando as variadas combinações de documentos referentes a cada corpo como "fichas", as quais formariam, reunidas, o conjunto que apresenta como sua "aldeia-arquivo". Mais do que instrumento de pesquisa, a "papelada" cuidadosamente selecionada e transcrita também é encarada como o objeto mesmo da investigação, pois a produção e o arquivamento de autos, guias, requisições e boletins são atrelados aqui ao conjunto de práticas que compõem a identificação dos não identificados; são compreendidos como ações construtoras dessa identidade específica.

Argumentando, então, que "cada identificação de um não identificado confere vigor a um modo específico de gerir estes corpos e suas mortes" (:34), Ferreira costura o enquadramento teórico-analítico de seu estudo. Desde a referência ao cadáver entregue à dissecação como espaço discursivo feita na introdução do livro, fica explícita a centralidade da obra de Foucault: a identificação dos não identificados é encarada como parte de processos de formação de Estado e produção de sujeitos e populações. A autora apresenta os corpos não identificados do IML-RJ (vulgarmente conhecidos como indigentes) como "corpos sujeitados e geridos por saberes e técnicas que tanto se propõem a administrá-los, quanto fazem por construí-los como tais" (:17) declarando que a análise em questão é informada por (mas não seria equivocado afirmar aqui o fato de ela estar também informando) referências de um quadro de gestão composto por outros corpos, como 
os "índios", os "menores", os "vadios" e os "loucos-criminosos", que habitam os trabalhos de Souza Lima, Vianna, Cunha e Carrara, respectivamente.

A influência foucaultiana impressa em todo o trabalho tem lugar especial na articulação do debate travado no primeiro capítulo do livro: "Identificando os não identificados". Tal processo de identificação é alinhado a técnicas de controle conformadas a uma racionalidade propriamente governamental: identificar, contar, documentar indivíduos constituem processos de produção de sujeitos - no plano de unidades isoladas; e de produção de populações - no plano totalizante de percepção e intervenção, configurando, assim, processos de formação de Estado. Em Dos autos da cova rasa, portanto, o Estado é entendido como um conjunto de práticas, algumas das quais aparecem como peças-chave desta engrenagem que identifica cada um (inclusive os "desconhecidos" já mortos) e os aloca em seus respectivos cadastros coletivos.

Ferreira descreve e discute uma série de técnicas que, ao mesmo tempo individualizantes e massificantes, entrecruzam-se neste arranjo dos mecanismos de controle governamentalizados. A recuperação da prática da datiloscopia, por exemplo, abre espaço para a discussão sobre a transformação da identificação criminal em identificação civil, demais estreitamentos entre a ciência da identificação e a criminologia, e ainda sobre imbricações entre os campos da medicina, do direito e da polícia. Um debate como este - tão indigesto quanto necessário - comunica ao leitor a força da tendência de "estatização do biológico", característica do séc. XIX, e seus formatos de atualização e amplificação através do combate às ameaças do desconhecido. Como controlar o que não se conhece?

O imperativo da legibilidade do todo e de suas partes alimentaria, então, as rotinas de trabalho de variadas repartições e aparelhos administrativos estatizados processo capturado pelas lentes de Ferreira ao analisar sua amostra. Desde a remoção de um cadáver de uma via pública ou de um hospital público para o IML-RJ até o enterro do mesmo em vala comum no Cemitério São Francisco Xavier (aquele "do Caju"), operava-se um processo formal e padronizado de identificação que a autora descreve de forma detalhada no primeiro capítulo e analisa enquanto "empreendimento classificatório" no seguinte.

"Os vários nomes do anonimato" foi o título escolhido para este segundo capítulo, cujo roteiro é pautado em função da exposição da lógica classificatória do processo de identificação, atrelada à entrevista que Ferreira realizou com um médico legista e situada através de uma recuperação da história do IML-RJ. A partir da análise da "aldeia-arquivo" e, em especial, da ficha "Aperj IML ec 0024/2647" - escolhida pelas questões que suscitou à pesquisadora ainda no período de levantamento do material - são enumeradas (e generosamente explicadas) dez características gerais da identificação dos não identificados. A primeira delas é a nomeação dos cadáveres com designações genéricas, como "Um homem", na ficha escolhida e em várias outras, ou outros nomes também bastante encontrados, como "Não identificado", "Um feto", "Recém-nascido", "Um menor", "Uma criança", "Uma mulher", "Homem", "Um homem completamente desconhecido", "Fulano de Tal" e ainda "João de Tal", "Maria de Tal", "Vulgo Bahiano" e "Jecatatu".

Também caracteriza a lógica classificatória descortinada por Ferreira o fato de as combinações de documentos de cada cadáver não se prestarem à sua individualização - configurando um "jogo classificatório" no qual frouxidão e inexa- 
tidão são parte do processo e não falhas. As outras características gerais destacadas são: a combinação entre a repetição de dados de cada corpo e a exibição do desconhecimento de informações através de lacunas e pontos de interrogação, por exemplo; a frequente presença de dados soltos em documentos; a economia de esforços por parte dos funcionários da organização envolvida nas trajetórias dos corpos (somada à descrença destes profissionais na utilidade dos documentos que produziam); a inadequação e o descuido material com os documentos; a serventia da produção destes documentos à exibição de um suposto controle (e cuidado) de corpos e territórios; o valor do procedimento de remoção - com destaque para a "guia de remoção" como marco inicial das trajetórias dos corpos como não identificados - o que antecipa a nona característica geral, que seria a importância desigual dos documentos arquivados.

O fato de a palavra "indigente" não aparecer como nome genérico nas fichas, apenas nas suas margens, em anotações ou carimbos, configura o décimo aspecto geral desta lógica classificatória - direcionando a pesquisadora à possibilidade da interpretação de "indigente" como "categoria geral" que, entre 1942 e 1960, reunia cadáveres nomeados com outras designações genéricas. Esta abrangência do termo fica ainda mais clara no terceiro capítulo, "O saber de uns, a morte de outros", quando o trabalho analítico é redesenhado a partir da reunião das fichas em cinco grupos específicos, dando continuidade à dissecação do material de pesquisa.

Esta divisão dos grupos, denominados pela autora a partir dos "nomes dados ao anonimato" dos não identificados, é apresentada como uma tipologia dos corpos e como possibilidade de reflexão sobre especificidades da concepção de morte envolvida em tal classificação. Argumentando que "não se separa das circunstâncias da morte a classificação do cadáver" (:104), Ferreira apresenta os grupos alinhavando suas reflexões a descrições analíticas, resumos e trechos das fichas. "Corpos Liminares" seriam aqueles que ainda não teriam nascido ("Um feto"; "Um recém-nascido"), cujas mortes são paradoxalmente colocadas em dúvida em seus registros; "Corpos Recusados" seriam aqueles cujos exames não foram realizados no IML-RJ (geralmente por não terem sofrido "morte violenta ou suspeita"), pré-classificação destacada pela autora por marcar eventualidades também conformadoras desse processo de identificação, paralelamente à lógica classificatória desvelada.

"Pernambuco" e "Orlando vulgo Treme Terra" foram nomes preenchidos em fichas que Ferreira reuniu no grupo "Corpos Conhecidos" por possuírem algum documento com dados a respeito dos corpos, desafiando seu completo desconhecimento; enquanto as fichas que, a despeito de apresentarem "nomes genéricos" como título, traziam em pelo menos um documento prenome e sobrenome (como "Octavio de Rocha Souza", removido como "Um homem" do Hospital Getúlio Vargas para o IML-RJ) foram reunidas como "Corpos Identificados". O grupo "Corpos Indigentes" reúne fichas nas quais todos os papéis arquivados só apresentavam nomes genéricos - grupo que compreenderia os outros quatro, pois mesmo quando se sabe o nome ou outra informação sobre o morto, esse dado é irrelevante, como se em vida essas pessoas também fossem irrelevantes aos olhos deste mesmo Estado que as aloca num genérico "desconhecido" após a morte.

Ao conectar suas considerações finais à pergunta "A quem serve a vala comum?", a autora ratifica a ideia da fixação dos não identificados num lugar social 
particular, afirmando que o processo de identificação por ela investigado colocase "como um agregado de procedimentos e registros burocráticos que marca, a um só tempo, corpos pessoais e desigualdades sociais" (:171). Redigido inicialmente como dissertação de mestrado, o trabalho que, como lembra no Prefácio a orientadora Adriana Vianna, causou espanto, hoje ocupa prateleiras obrigatórias para estudos sobre administração pública, gestão de populações, assimetrias sociais e Estados - no plural.

HARRIS, Mark. 2010. Rebelião na Amazônia. Cambridge: Cambridge University Press. 302 pp.

\section{James Andrew Whitaker}

Doutorando, Departamento de Antropologia,

Tulane University, New Orleans

Este é o livro mais recente de Mark Harris a envolver-se com debates relativos à floresta amazônica e seus povos. É o primeiro livro em inglês que toma como tema fundamental um paroxismo específico de rebelião que ocorreu na Amazônia brasileira durante a década de 1830. Iniciada em 1835 com a queda de Belém, a revolta veio a ser conhecida como Cabanagem nas décadas posteriores do século 19. Este termo significa "a atividade das pessoas que moram em cabanas, a habitação mais pobre da região" (:5). Harris apresenta uma explicação densa e sociologicamente detalhada desta rebelião. Em relação ao período mais amplo de história brasileira, no qual a Amazônia e a Cabanagem estão entrelaçadas neste trabalho, Harris tenta "mostrar como o sucesso da economia da borracha se tornou possível pela persistência de valores camponeses e a sujeição da região" (:9).

A pesquisa que fundamenta este livro abrange tanto fontes primárias quanto secundárias. Harris usou materiais de arquivos locais bem como nacionais. No entanto, ele explica que muitos dos documentos locais relevantes, que poderiam ter oferecido informação importante sobre o contexto, foram destruídos pelos rebeldes durante a Cabanagem. Histórias orais não foram utilizadas na preparação deste livro em conformidade com o foco na historiografia brasileira. No entanto, em algumas poucas passagens, tais como na discussão sobre os canhões falsos usados em Ecuipiranga (:254), há referências à história oral. As notas sobre fontes de Harris são detalhadas no que se refere ao conteúdo e à localização do arquivo; elas serão de grande valor para futuros pesquisadores.

O rio Amazonas é um símbolo poderoso de confluência não fixa. Harris escreve que "o rio não era apenas o palco onde a vida transcorria, ele também escrevia a peça e atuava na apresentação" (:104). Mobilidade e fluidez são apresentadas como temas que conectam e interrompem aspectos geográficos, sociais, políticos e econômicos da sociedade paraense. No entanto, subjacente a esse exterior fluido, há interesses opostos, a maior parte deles relativa ao controle e à utilização de trabalho e terra, que tomaram forma ao longo do tempo para produzir cisões tanto em nível provinciano quanto nacional. A mobilidade atenuou as tensões até certo ponto. Em parte devido à paisagem ribeirinha, as elites ficaram bastante perplexas nas suas tentativas de estabelecer uma forma de vida fixa e sedentária no Pará. Os padrões paraenses mutantes de circulação, interação, expressão religiosa e mesmo linguagem parecem ter sido caracterizados pela mistura fluida, empréstimo e fronteiras porosas.

Harris cuidadosamente identifica e avalia a forma mutável de divisões sociais (baseadas em raça, classe e etnicidade) na sociedade paraense. Em relação a 